\title{
Optimizing the Event Set for Collegiate Aviation FOQA Programs
}

\author{
JD Swinney \\ Kansas State University - Salina
}

\begin{abstract}
Flight Operations Quality Assurance or FOQA is a proven tool in the effort to enhance aviation safety. Employed by air carriers as early as the 1960's, FOQA allows aviation operations and safety managers to objectively monitor how their aircraft are being operated. This data can then be translated into informed decisions to improve the safety and efficiency of the overall operation. While FOQA has proven itself in the world of airlines and other commercial aviation ventures, these flight data monitoring programs have largely been absent in the area where the vast majority of flight operations occur, general aviation. Advancements in technology allow those in general aviation management positions the ability to apply the same techniques in general aviation. This study attempts to further the body of knowledge of Flight Operations Quality Assurance (FOQA) programs by examining the unique requirements of a FOQA program adapted to the university flight-training environment. The methodology employed are qualitative in nature employing a Delphi study to gather data from a group of subject matter experts on both FOQA and general aviation flight instruction. Qualitative observations gathered by the researcher from the direct observation of flight instruction will be used to supplement the data gathered from the Delphi Study. Through the analysis of these two data sets, this study determines what events and parameters should be monitored in a collegiate FOQA program.
\end{abstract}

\section{Introduction}

Reports produced by the National Transportation Safety Board (NTSB) and the Air Safety Institute (ASI) have shown that aviation accidents have decreased sharply since the 1960s, but the data also shows that between 60 and 80 percent of accidents are attributed to human error. (NTSB, 2012). Advancements in technology, both mechanical and electronic in nature, have contributed to the decrease in the overall accident rate, however, the high percentage of human error that remains shows that in order to decrease the accident rate further we must focus on mitigating the behaviors that often result in aviation accidents.

Flight Operational Quality Assurance (FOQA) programs present a solution to this problem; already in place in many airlines and commercial aviation enterprises throughout the world, they have proven their ability to break the chain of mistakes that lead to an accident. FOQA provides aviation managers a proactive method of safety management through the monitoring of recorded data showing trends in pilot behaviors. 
FOQA programs are generally limited to airlines and large commercial aviation ventures, and are largely absent from university aviation programs and the general aviation community. There is an array of reasons why FOQA is not in wide use in general aviation, the most prominent of which is the initial cost to implement a FOQA program. Implementation costs include the analysis software and administrative processes required to manipulate the recorded flight data as well as equipment in the aircraft that will record the in-flight data. Previous studies have explored the efficacy of using the built-in data recording functions found in modern EFIS or "glass cockpit" avionics packages as the technology platform of an FOQA program. (Lau, 2012). What is lacking from the body of knowledge is a study of the unique situations faced in collegiate flight training, and how an FOQA program can be tailored so they not only increase the overall safety of an organization, but also to aid students in attaining the flight proficiency required of a commercial aviator more quickly and efficiently.

The results of this study can be used to help the management of a collegiate flight training organization determine how best to focus its resources to correctly monitor flight training activity. The methodology used in this study places an emphasis on determining the set of events that must be developed and monitored by a university FOQA program in order to provide program administrators and safety personnel a snapshot of trends that could potentially lead to an accident.

\section{Review of Literature}

FOQA is a voluntary safety program that intends to make aviation safer through the gathering and analysis of objective and quantitative data (Vala, 2011). FOQA programs have been commonplace in European air carriers since the 1980s and US air carriers since the 1990s. Since the early 2000s, FOQA programs have begun to take root in smaller commercial aviation operations and will eventually be applicable to the larger general aviation community. Expansion of FOQA into General Aviation (GA) is not without its challenges, but research shows that FOQA and the opportunity it provides to objectively review day-to-day flight operations represents the most realistic solution for reducing general aviation incidents from their current levels (Mitchell, Stoly \& Stolzer, 2007).

The causal factor of roughly $80 \%$ of accidents in both civil and military aviation are mistakes made by the flight crew (Ramana, n.d.). By addressing these accidents related to human error through the proactive data collection FOQA enables, aviation managers hope to significantly reduce aviation accidents. Most of these accidents are attributed to deviation from standard operating procedures, failure to conduct operations critical to the flight at the prescribed time, and rushed performance during critical phases of flight (Harrah \& Kaseote, 1999). FOQA allows aviation managers to view this substandard performance in the aggregate. With FOQA aviation managers can track trends, conduct statistical analysis, and quantify the areas of pilot performance that require additional safety training or a change to the company's standard operating procedures. Through this 
simple concept, aviation managers have the opportunity to influence pilot behaviors that could lead to an accident prior to the accident happening.

This study focuses on FOQA and its use in general aviation. General aviation is commonly defined as "all air traffic that is not either military or scheduled air service and comprises the majority of aviation operations that take place in the U.S. on a daily basis. (Wensenveen, 2011) In contrast to the safety enhancements and reduced accident rates attributed to FOQA programs and their use in the air transportation industry, the general aviation community has not enjoyed the same benefits. The current technological environment provides a means to change this fact due to emerging technologies.

S. Lau's study (2007) states: Currently, there is a confluence of events that make FDM practical for General Aviation aircraft. These events include a new sophisticated approach to aviation safety by operators and the FAA, affordable computing power and storage, high-speed internet connectivity, precise GPS navigation capabilities, open aircraft systems architecture that allows data acquisition from a digital avionics data bus and the miniaturization of sensors to create new lightweight low- cost devices with accuracy that rivals more expensive inertial measurement units. (pg. 4)

The application of these new technologies will allow the general aviation community to share in the benefits of FOQA which include safety, efficiency, and enhanced maintenance management.

As research points to the benefits of GA FOQA, collegiate aviation provides the perfect proving ground for GA FOQA programs due to the comparatively large size of university aircraft fleets. Some of the first steps in the advancement of GA-FOQA as it applies to collegiate flight programs were taken by the University of North Dakota, Purdue University, and Embry Riddle Aeronautical University. (Lau, 2012) These initial studies provided a proof of concept in relatively low cost GA-FOQA using the flight data monitoring capabilities of the Garmin-1000 digital cockpits as well as Lightweight Aircraft Recording Solutions (LARS) from companies such as Alakai and Appareo. This proof of concept has shown that FOQA programs can increase the efficiency of general aviation operations through reduced maintenance troubleshooting costs and decreased aircraft on ground (AOG) times. (Lau, 2012).

FOQA is important to collegiate flight programs for reasons apart from the safety and efficiency gains that can be realized. According to a 2007 newsletter published by the Aviation Accreditation Board International an industry panel suggested that students expected to function effectively in an industry where flight data monitoring is the norm should be exposed to FDM and FOQA at the university level (AABI, 2007). By developing and maintaining an FOQA program, a university can train its students in flight data monitoring techniques and expose them to the data mining process. 
Universities can also improve students' perceptions toward their future employer's FOQA programs through exposure to FOQA in their initial flight training.

A challenge facing collegiate FOQA programs is the relative newness of the technologies that make general aviation FOQA possible. There have been few studies completed on collegiate FOQA (Vala, 2011). This challenge establishes the need for this study; for an FOQA program to be an important part of collegiate flight training and general aviation it must be structured so that aviation managers are viewing data that is optimized to their operation

\section{Methodology}

This study employs two qualitative methods. A Delphi study and a series of qualitative observations were run concurrently. The methods were employed simultaneously, but could have been employed sequentially had more time been allotted for the conduct of the study.

Part one of the study includes a Delphi study to gain a consensus from a group of recognized subject matter experts in the areas of flight instruction and FOQA. Two primary characteristics of a Delphi study are that it is a multi-round study that provides feedback to the participants, and that the participants are anonymous to one another. A Delphi study fit this particular study nicely allowing the researcher to collect data from a panel of experts, and the anonymity between participants allowed each participant to express their views without those views being skewed by other participants. The panel is made up of eight participants of various backgrounds, in order to pull data from the diverse range of general and collegiate aviation. The panel includes university flight safety officers, university flight and ground instructors, and aviators with a background in flight-testing and the airline industry.

Delphi studies are characterized by the small size of their panel of participants. Therefore, a Delphi study is not designed to produce statistically significant results, but to produce a snapshot of the opinions of a given panel of subject matter experts. Due to this fact participant selection for a Delphi study is of utmost importance. (Gordon, 1994) 10 individuals were selected and asked to participate in the study, of which eight responded favorably to the request and agreed to provide data. Of the eight individuals who provided data for round one of the Delphi Method, only six updated their responses for round two, with the remaining two participants electing to leave their round one responses unchanged. The resulting data was adequate for the purposes of the research as the responses were very similar in nature and pointed to clear conclusions. This researcher believes that any richening of the data set that could have been provided by a larger panel is offset by the data provided by the qualitative observations employed during this study that strongly correlated with the data from the Delphi study.

Selecting the appropriate subject matter experts was crucial to the study. Participants were selected that had experience in collegiate aviation and understood its challenges and 
environment. These subject matter experts were either actively employed as flight instructors in a university aviation program, or were active researchers or safety managers of a collegiate aviation program. Secondly, participants were selected for their knowledge and experience with general aviation FOQA. This researcher believed the study required participants who had either research or practical experience in the fields of GA and collegiate aviation FOQA in order to provide data that would directly support the research questions. Lastly, this researcher wanted to include a few individuals who were outside the spheres of collegiate aviation and FOQA. Participants were selected who had practical experience in the research topic, but could provide outside experience and a divergent view on FOQA. It was believed that participants of this type would provide differing viewpoints that would serve to richen the resulting data. The final panel selected fit the Delphi Methodology requirement of a small panel of experts in their field and was comprised of four collegiate FOQA managers or researchers, two senior collegiate flight instructors, a flight test engineer with experience in military and airline FOQA, and a GA writer and advocate.

Only two rounds of response and feedback were required in this Delphi Study due to the relatively unchanging nature of the responses from the participants and their similarity to one another. An analysis of the feedback to each question was completed by finding the amount of times a similar theme appears in the responses to each survey question and dividing by the total number of panel members. This analysis gave the researcher a percentage based score that was used to judge the similarity of the survey responses. Through this process this researcher was able to draw conclusions based on the relative frequency of a particular response.

Qualitative observations were used to supplement the data gathered in the Delphi study. The data collected from the Delphi study is the more important dataset given the expertise and diversity of the panel members, but qualitative observations taken by the researcher from actual flight training situations worked to overcome the small sample size inherent to the Delphi study.

The methodology behind the qualitative observations involved this researcher observing training flights from the rear seat of a training aircraft to record interactions between the flight instructors and students. The researcher recorded corrections made by the flight instructor to counter mistakes made by the students. These corrections were of a verbal nature or in the form of physical manipulation of the flight controls. The researcher coded the various corrections observed on a thematic basis with the theme denoted by the maneuver being corrected and the type of mistake made by the student during the maneuver. Following the coding of the observations, the researcher analyzed the observed corrections in aggregate. It was assumed that mistakes that were commonly made by students would be marked by an increased number of corrections made by the flight instructor and those student pilot behaviors most often corrected by the flight instructor should be monitored by the FOQA program. 


\section{Results}

The findings of the Delphi Study are presented in this section and organized to show the responses of the panel members grouped into themes. The responses in this section are paraphrased to more clearly portray the data provided by the respondent and presented in a question and answer format that fits the survey instrument used in the study.

Question 1: What specific flight maneuvers or types of flight maneuvers are difficult for a flight instructor to objectively evaluate and critique.

$100 \%$ of respondents stated that complex maneuvers with multiple variables such as a chandelle or lazy eight are the most difficult for a flight instructor to objectively evaluate. Every participant also stated that ground reference maneuvers are difficult to judge. Steep spirals were specifically mentioned by all participants due the difficulty in the instructor's determination of the precise ground track during the course of the maneuver.

Five out of six participants in round two indicated that approaches of various types are difficult to objectively evaluate. The approaches discussed varied from steep VFR approaches to instrument approaches. The reasons indicated by the participants center on the number of variables present during the approach. Participants indicated that a synthesized picture of the approach recreated for use during the flight debrief would be helpful to both students and instructors.

Outlying responses mentioned by two or fewer of the participants include emergency maneuvers and holding pattern entries and procedures. It was indicated by these participants that emergency procedure training such as landing site selection could benefit from recorded ground tracks and synthesized playback.

\section{Question 2: Discuss some of the limitations you regularly see exceeded while flying with student pilots. (These limitations can either be specific to a standard operating procedure or specific to the aircraft)}

Five out of eight participants responded to this question by indicating that flap extension speeds are the most common aircraft limit exceeded by student pilots. The same number of participants report that altitude and heading are two other very common maneuver limits exceeded by students. $50 \%$ of the participants indicate that engine RPM over-speed is a common occurrence. Outlying responses provided by only one participant are bank angles in the traffic pattern and autopilot engagement altitudes. 
Question 3: From the event list provided in the survey instructions, what other events do you believe should be included (a copy of the KSU Salina FOQA event set was provided to the study participants). To clarify, what should be monitored that is not captured in the listed events? (Do not focus on "how" something could be monitored with the listed parameters, but list "what" you believe should be monitored)

The responses from this question were not as similar as the responses to the previous questions where a clear majority of participants provided the same response. The responses do however correlate with the responses given to previous questions. The most common responses to Question 3 indicated that events monitoring unstabilized approaches and flap extension speeds are very important to a collegiate FOQA event set. Participants further recommend that events monitoring how the aircraft is controlled in the landing phase be added. Specifically, three participants recommended events be developed to monitor the G loading of the aircraft when it is landed to track "hard landings" as well as examining the length of the landing to monitor how often the aircraft is landed beyond the intended touchdown point. Responses given by two or fewer participants include the addition of events that track compliance with the school's operations or procedures manual. Bank angles during turns in an airport's traffic pattern are also provided as an issue that requires monitoring.

Participants mentioned he Nall report prepared by the Air Safety Institute as a document from which events could be developed, the Nall report is an annual document that outlines General Aviation accidents from the previous year. (Air Safety Institute, 2012) The accident data contained in this report provides data on the most frequent general aviation accidents and could provide a guide for what should be monitored by a general aviation FOQA program.

Question 4: The G1000 provides the capability to record parameters such as fuel flow, EGT/CHT, RPM, OIL Temp, and Outside Air Temp (see parameter list in the attached survey instructions). How could this data concerned with engine operation be used in a collegiate flight-training program?

All participants agreed that parameters relating to the power plant of the aircraft should be used to monitor the leaning and fuel efficiency of the engine. Participants further explain this answer by indicating that the grouping of multiple parameters such as fuel flow, GPS location, and altitude could be used to monitor mixture leaning during ground operations. The majority of participants also respond that engine parameters could be used to develop an engine health-monitoring program or to monitor the efficiency of operations such as tweaking the locations where flight training is conducted or how the aircraft's performance is managed to make the overall operation more efficient. 
Question 5: What is the primary safety related concern of the flight training operation in which you are/were involved?

The participants in the survey all answered this question in differing ways but the responses coalesce around two primary themes. The first theme is that a primary safety concern for many aviation operators is the deviation of pilots from standard procedures found either in operations manuals and/or local procedures guides. Other events cited include improper landing of the aircraft and unstabilized approaches.

Question 6: What student action(s) do you believe are most often related to the incidents or accidents experienced in a flight-training program?

The majority of participants respond that poor task management or judgment on the part of the student contributed to the majority of incidents and accidents in flight training programs. Poor judgment is expanded upon to refer to students who knowingly operated the aircraft outside of policies and procedures established by the school. This could include flight into bad weather, landings conducted with excessive crosswind components, or intentional aggressive maneuvering not required by the flight conditions.

Pilot complacency is another danger identified by the participants; this statement led into discussions of improper task management during periods of high workload. It was suggested by one participant that FOQA could be used to track minor excursions outside of established standards and that data studied against perceived workload levels.

Question 7: The Garmin G1000 provides the ability to record parameters such as which navigation source is selected, when the autopilot is engaged/disengaged, CDI deflection, etc. (See list of available parameters in the survey instructions) How could these measurements concerned with resource and avionics management be used by flight instructors and training program managers to improve safety and training efficiency?

All participants agree that this information could be used to monitor automation usage. By monitoring automation usage, program managers and instructors could determine if students are using the automation correctly and not over-relying on a particular function of the automation. Through the monitoring of automation usage to this level of detail program managers could determine if students displayed an over-reliance on one function of the automation without learning the system in detail. Autopilot usage could also be determined with the goal of monitoring the amount of autopilot usage and whether the autopilot is used in accordance with manufacturer and local procedures.

The results of the qualitative observations are presented in graphic form where possible. The goal of the qualitative observations was to determine what trends were present in the mistakes and corresponding corrections made by students and instructors during actual flight training so that those results could be compared to the feedback from the Delphi study. 35 flight hours of observations were taken over the course of two 
months during collegiate flight instruction. The students observed include those who were receiving primary, commercial, or instrument training.

The corrections and student mistakes are coded thematically based on the nature of the correction and compared on a percentage basis against the total number of corrections observed. This simple comparison provides insight into what mistakes are most common among student pilots in collegiate flight training and subsequently where the focus of collegiate flight training FOQA programs should lie. Figure 2 provides a graphic depiction of the categories of corrections observed and how they relate on a percentage basis to the other categories.

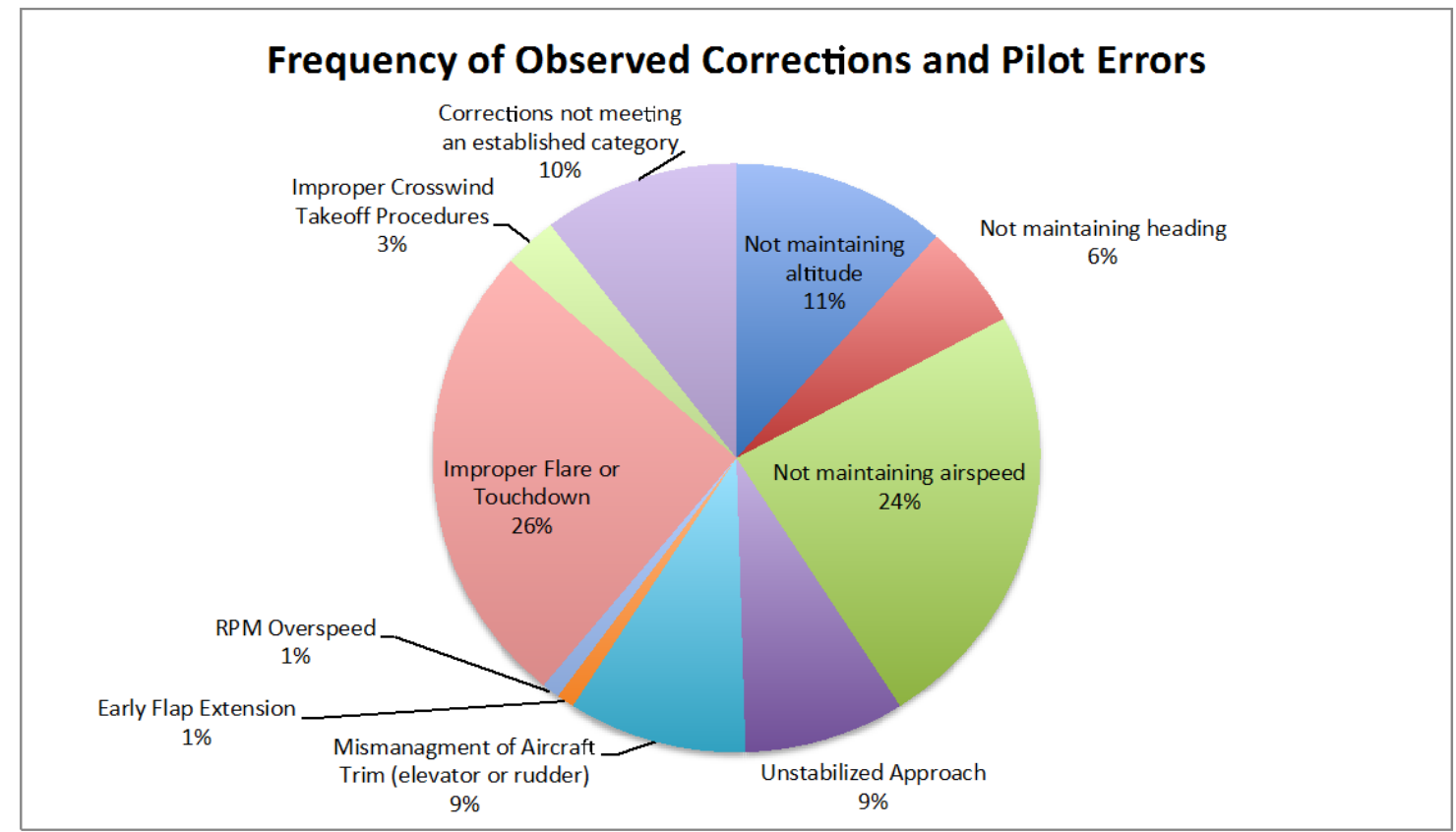

Figure 1. Frequency of Observed Corrections and pilot errors.

The above figure describes the nature of mistakes made by student pilots. A pilot action is classified as an error if it results in a situation where the aircraft is operated outside of established local or FAA standards for the maneuver being performed. The researcher expands the analysis of pilot behavior to account for the skill level of the student pilot. A pilot's skill level refers to the level of airman certificate held or level of training being conducted such as private or commercial pilot. Pilots operating at or training for the commercial pilot skill level must operate the aircraft to a more stringent set of standards than those pilots operating at the private pilot skill level.

$50 \%$ of the total corrections and mistakes observed are comprised of mistakes related o the landing of the aircraft from the landing flare to touchdown and mistakes relating to insufficient control of airspeed comprising $26 \%$ and $24 \%$ of the total number of corrections respectively. Errors involving insufficient maintenance of aircraft altitude, 
the trimming of both the aircraft's elevators and rudder, and those involving the student conducting an un-stabilized approach each accounted for approximately $10 \%$ of the total number of observed pilot errors. Of the other themes in pilot errors that are observed, each accounts for less than $10 \%$ of the total number of observed errors.

Additionally, many actions were observed that do not fit into any of the established categories. These actions generally relate to situations where the pilot action was incorrect but did not result in the aircraft being operated outside of a local or FAA standard. These incorrect actions relate to generally accepted safe operating practices such as aircraft bank angles or engine management procedures. The researcher believes that the creation of a separate category for each of these errors might have made the overall analysis of the data less clear to the reader.

The researcher believed that to provide an analysis of the pilot errors observed relating to improper flare and touchdown the observed errors should be shown graphically to provide insight into the exact nature of the error made by the student pilot during the landing phase. This breakdown is shown in figure two.

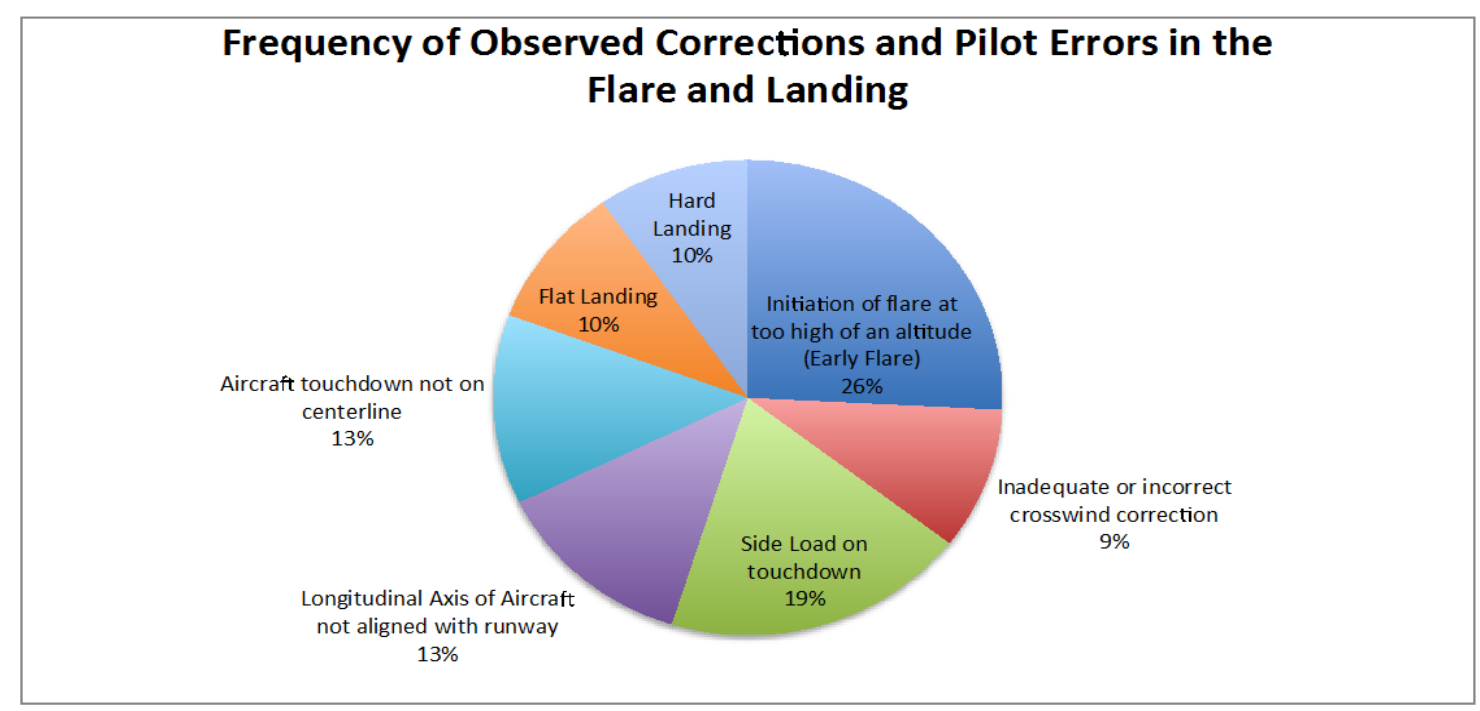

Figure 2. Frequency of Observed Corrections and Pilot Errors in the flare and landing.

The reader should note that of the corrections observed during the landing phase, many are the result of interrelated factors such as the flaring the aircraft at too high of an altitude resulting in a hard landing. To decrease any confusion in the interpretation of the data, each pilot error or instructor correction is viewed as a single event.

The majority of pilot errors observed during the landing phase relate to the student pilot initiating the flare maneuver too early or at too high of an altitude above the runway accounting for $26 \%$ of the overall errors observed. Landing of the aircraft with lateral "G" forces or a "side-load" attribute to the second most often observed error at $19 \%$ of 
the total errors observed. Other errors observed each account for between $9 \%$ and 13\% of the total number of observed errors.

\section{Conclusion}

This researcher endeavored to present an event set that is specific enough to be useful to the collegiate FOQA manager. However, there are multiple flight data recording solutions available that are viable for use in light airplanes, and the researcher did not attempt to tailor an event set for multiple data recording solutions. It is up to the individual FOQA manager to assemble the available parameters of their recording solution to meet the events recommended by this study. The suggested collegiate FOQA event set as defined by this study is contained in table 1 .

Though not the traditional objective of FOQA programs, it was suggested by Delphi study participants that the use of recorded flight data could prove very beneficial while debriefing the training flight to the student pilot. This information could allow the CFI to construct either a virtual model of the flight to the student, or a graphic of the aircraft's track across the ground during the maneuver to aid in objectively explaining the performance of the maneuver. The difficulty in using a FOQA program and recorded flight data in this manner is the rapidity with which the information must be retrieved from the recording device in the aircraft. Furthermore, the flight data recording and analysis system in use must be compatible with the software used to display the flight information in the graphic format required of student debriefs. Stated another way, the technology used to record and analyze the flight information must be able to retrieve the information from the aircraft and process it quickly enough to be used to debrief the student immediately following the flight.

The use of recorded flight data during student debriefs is an area where further research is required. Aviation managers should investigate how to integrate this technique into a flight-training syllabus. It is this researcher's hypothesis that through the proper use of recorded flight data the average training time required for a student to attain pilot certificates could be reduced.

The use of FOQA programs is a promising method in the effort to reduce the training time and resources required in a collegiate flight-training syllabus. FOQA represents a very realistic opportunity to reduce the number of accidents in the general aviation community as a whole. Collegiate aviation with its relatively large fleets of training aircraft and large student population provides an excellent proving ground for general aviation FOQA techniques, and the lessons learned from collegiate FOQA programs can be applied to the general aviation community as a whole. This study provides a template and recommendations on FOQA events that are best suited to a collegiate FOQA program, but leaves the final analysis of the importance of each event to the FOQA

manager. This is an important distinction because although at their core the FOQA programs of all flight-training operations will share many similarities, each program is 
different in terms of training goals and environments and therefore will require a slightly different approach from the FOQA manager. 
Table 1

Recommended events in a collegiate FOQA program.

\begin{tabular}{|c|c|c|}
\hline Event Title & Event Logic & $\begin{array}{l}\text { Parameters Used } \\
\text { (suggested) }\end{array}$ \\
\hline $\begin{array}{l}\text { Unstabilized } \\
\text { Approach }\end{array}$ & $\begin{array}{l}\text { Greater than 500FPM descent, too } \\
\text { fast on final approach }\end{array}$ & airspeed, vert. speed \\
\hline Flap Extension & Flaps extended above Vfe & airspeed, flap indications \\
\hline RPM Overspeed & Engine RPM above maximum level & Engine RPM \\
\hline $\begin{array}{l}\text { Bank Angle in } \\
\text { Traffic Pattern }\end{array}$ & $\begin{array}{l}\text { Greater than } 30 \text { degree bank in traffic } \\
\text { pattern }\end{array}$ & bank angle, geo-location \\
\hline $\begin{array}{l}\text { Fuel Mixture } \\
\text { Leaning }\end{array}$ & Mixture not leaned in cruise flight & fuel flow, Altitude \\
\hline $\begin{array}{l}\text { Fuel mixture } \\
\text { leaning (ground) }\end{array}$ & $\begin{array}{l}\text { Mixture not leaned during ground } \\
\text { operations }\end{array}$ & $\begin{array}{l}\text { fuel flow, altitude, geo- } \\
\text { location }\end{array}$ \\
\hline Autopilot Usage & $\begin{array}{l}\text { Autopilot not used below minimum } \\
\text { altitude }\end{array}$ & autopilot, altitude \\
\hline Excessive Bank & Bank Angle greater than 60 deg & Bank angle \\
\hline Excessive Pitch & $\begin{array}{l}\text { Pitch Angle greater than }+30 \text { deg or - } \\
15 \text { deg }\end{array}$ & Pitch attitude angle \\
\hline VNE Max & Airspeed greater than aircraft Vne & Airspeed \\
\hline $\begin{array}{l}\text { Excessive G } \\
\text { Loading }\end{array}$ & G loading greater than 2.5 & Vertical G Force \\
\hline Fuel Low & $\begin{array}{l}\text { Fuel level below } 1 \text { hour of normal } \\
\text { cruise fuel burn }\end{array}$ & fuel level \\
\hline Hard Landing & $\begin{array}{l}\text { Landing with a momentary G loading } \\
\text { of greater than } 1.5\end{array}$ & Vertical G force, altitude \\
\hline $\begin{array}{l}\text { Side Load on } \\
\text { Landing }\end{array}$ & Landing with lateral G forces & Lateral G, altitude \\
\hline $\begin{array}{l}\text { Excessive float } \\
\text { on landing }\end{array}$ & $\begin{array}{l}\text { Touchdown beyond the } 1000 \text { ' marker } \\
\text { on the runway }\end{array}$ & $\begin{array}{l}\text { Altitude, Location, } \\
\text { Airspeed }\end{array}$ \\
\hline Flat Landing & $\begin{array}{l}\text { Touching down on nose wheel } \\
\text { simultaneous with main gear }\end{array}$ & Altitude, location, pitch \\
\hline CHT Max & CHT above aircraft maximum level & CHT \\
\hline EGT Max & EGT above aircraft maximum level & EGT \\
\hline High Oil Temp & $\begin{array}{l}\text { Oil Temp above manufacturer's } \\
\text { specified level }\end{array}$ & Oil Temp \\
\hline Oil Pressure Low & $\begin{array}{l}\text { Oil Pressure below manufacturer's } \\
\text { specified level }\end{array}$ & Oil Pressure \\
\hline Cont'd & Cont'd & Cont'd \\
\hline
\end{tabular}




\begin{tabular}{|l|l|l|} 
Event Title & Event Logic & $\begin{array}{l}\text { Parameters Used } \\
\text { (suggested) }\end{array}$ \\
\hline Oil Pressure High & $\begin{array}{l}\text { Oil Pressure above manufacturer's } \\
\text { specified level }\end{array}$ & Oil Pressure \\
\hline Voltage Low & $\begin{array}{l}\text { Voltage below manufacturers } \\
\text { specified level }\end{array}$ & Voltage \\
\hline Amperage Low & $\begin{array}{l}\text { Amperage discharging after a given } \\
\text { amount of time in flight }\end{array}$ & Amperage, elapsed time \\
\hline
\end{tabular}




\section{References}

Air Safety Institute. (2012) The $22^{\text {nd }}$ Joseph T. Nall Report: General aviation accidents in 2010. Frederick, MD: AOPA Foundation.

Federal Aviation Administration. Lowe, S., Pfleiderer, E. M., \& Chidester, T., (2012, JAN). Perceptions and efficacy of flight operational quality assurance programs among small-scale operators. Retrieved from: http://trid.trb.org/view.aspx?id=1136101

Gordon, T. J. (1994). The Delphi Method. AC/UNU Millennium Project. Futures research methodology, 1-9.

Harrah, R.A., Kaseote, G. (1999, May). A case for higher data rates. International symposium on transportation recorders. (pp. 1-8) Arlington, VA: National Transportation Safety Board.

Industry/educator forum and the pilot supply pipeline (2007, March/April). Inside AABI The Newsletter on Worldwide Aviation Accreditation. Retrieved from http://www.aabi.aero/News\&Calendar/InsideAABI\%203-2007.pdf

Jewell, P.J. Young, J.P. Flight operational quality assurance: Data analysis, implementation, and role in a collegiate flight training environment. (Master's Thesis) Retrieved from Purdue University e-Pubs.

Lau, S. (2012, Jan). Flight data monitoring: General aviation safety information analysis and sharing research project. Prepared by CAPACG, LLC. Daytona Beach, FL: Embry Riddle Aeronautical University.

Lau, S. (2007). Fly with intelligence: Best practices to improve the safety and efficiency of flight operations. Prepared by CAPACG, LLC. Daytona Beach, FL: Embry Riddle Aeronautical University.

Mitchell, K., Sholy , B., \& Stolzer, A. (2007, June). General aviation flight operational quality assurance: Overcoming the obstacles. IEEE and A\&E Systems Magazine, 22(6), 09-15. doi: 10.1109/MAES.2007.384075

National Transportation Safety Board. (2012). Aviation Statistical Reports [data sets]. Retrieved from http://www.ntsb.gov/data/aviation_stats.html

Ramana, M. (n.d.). Flight operational quality assurance through the exploitation of flight data recorders. Retrieved from http://www.quest global.com/downloads/Flight_Operational.pdf 
Rantanen, E, Taylor H.L., Bradshaw G.L. Emmanuel T.W., Lendrum L, \&Hulin C. Derivation of Pilot Performance Measures from Flight Data Recorder Information. Lecture presented at 11th International Symposium on Aviation Psychology. The Ohio State University. Columbus. 2001.

Tsurata, G. (2009). The analysis of flight operations quality assurance data. Saarbrucken, Germany: VDM Verlag \& Co.

U.S. Federal Aviation Administration, (2004). Advisory circular 120-82 flight operations quality assurance. Washington, DC: Department of Transportation.

Vala, L. (2011) Flight operational quality assurance for university operations. (Master's thesis). Retrieved from Purdue University E-Pubs. (Paper 38) http://docs.lib.purdue.edu/techdirproj/38

Wensveen, J.G. (2011). Air transportation: A management perspective $-7^{\text {th }} e d$. Ashgate Publishing Co. Burlington, VT. 